\title{
Computer Assisted Programmed Instruction and Cognitive Preference Style as Determinant of Achievement of Secondary School Physics Students
}

\author{
Sotayo, M. A. $O$. \\ Federal College of Education, Osiele, Abeokuta, Nigeria
}

\begin{abstract}
The study probes into the effect of Computer Assisted Instruction and Cognitive preference style on achievement of secondary school Physics Students in Ogun State of Nigeria. The population of the study comprises the SS II students in Abeokuta Educational Zone. 186 students sample were drawn from the population for the study. Two main valid and reliable instruments were used for data collection: Physics Achievement Test $\left(\mathrm{KR}_{20}=0.83\right)$ and Physics Cognitive Preference Style Inventory $\left(\mathrm{KR}_{20}=0.86\right)$. The result revealed significant main effect of treatment $[\mathrm{F}(1,186)=28.651, \mathrm{P}<0.05]$ and cognitive preference style $[\mathrm{F}$ $(3,186)=23.349, \mathrm{P}<0.05]$ on physics achievement. The data collected were analysed by two-way analysis of variance. The analysis showed that the Computer Assisted Programme Instruction group achieved significantly higher than the conventional group. However, Post hoc analysis showed that the mean score of students with questioning learning mode achievement was significantly higher than those of recall and principle respectively. The achievement of students of application learning mode was also significantly higher than those of recall and principle respectively. There was no significant interaction effect between Cognitive Preference Style and Computer Assisted Programmed Instruction. The implications of the result to the stakeholder were discussed.
\end{abstract}

Keywords: computer assisted programmed instruction, cognitive preference style, achievement in physics

\section{Background to The Study}

Throughout the world science is witnessing a decline as science departments close down (Main, 2005). This is happening when the whole world is yearning to train more scientists, especially the physical scientist. Despite the dominant role of science in the development of nations, physics -a very important science subject is associated with low student enrolment and performance (Iroegbu, 1998; Orji 1998).

This problem has attracted the attention of many researchers (Otuka, 1987; Okpala and Onocha, 1998; Farayola 2003). Some of them have identified the source of the problem to include, among others, the use of lecture methods, lack of teaching facilities, incompetent teachers, poor funding, inability of students to understand science concepts etc.

In an attempt to solve the problem, science educators noted that the use of lecture method in teaching the subjects makes a wide range of students who have moderate numerical ability and different cognitive preference style to view physics as difficult, unimaginative, hard to understand and requiring much memorization and quantitative ability. In consequence, the studies recommended a practical approach to the teaching of physics, particularly at the secondary school level. This study emphasizes the need to investigate the impact of Computer Assisted Programmed Instruction, on achievement of physics students, more so when such strategy has potentials for cultivating and grooming the discipline of self-directed study in an academic field as well as enhancing learners' level of cognitive development (West, 1992).

In spite of the possible influence of Computer Assisted Instruction on Achievement in physics, researchers (Onocha and Okpala 1996; German, 1998) have also identified that learner characteristics can affect achievement in physics. This study is interested in how to empower physics students to improve on achievement in heat related concepts, it is therefore necessary that the study focuses on a learner characteristics that is concerned with conceptualization of learning 
environment. This characteristic is cognitive preference style. This is particularly important because science learning is becoming increasingly conceptual (Sarcho and Spodeck 1981).

Cognitive preference style is the characteristic way in which an individual prefers to learn a new material (Jugwirth, 1980). This implies an individual's learning modes. These learning modes according to (Heath, 1964 and Jungwirth, 1980); include Recall (R), Principle (P), Application (A) and Questioning (Q). Recall is associated with learners who accept information as it is without considering its implication or application. Recall-oriented learners show preference for learning names, formulae, definitions, fact etc. Principle $(\mathrm{P})$ is associated with learners who accept information which illustrates or exemplifies fundamental rules based on concepts or relation between variables or rules applicable to class of objects. While Application (A) is associated with learners who tend to accept information which emphasizes application or usefulness in a given context (e.g. solving daily problems). Questioning is associated with learners who tend to critically question any information for validity, reliability, completeness, limitations etc, perhaps with a view to raising suggestions for improvement or generating hypotheses. Thus cognitive preference style suggests how a learner processes information intellectually. This method of processing information (learning modes) could depend on learning experiences (Tamer 1976). It is therefore possible for learning mode to interact with learning experiences associated with computer programmed instruction to influence physics students' achievement. This possibility was investigated in this study.

\section{Statement of Problem}

The study therefore seeks to determine the effect of computer assisted programmed instruction and students' cognitive preference style on students' achievement in physics.

Hypotheses:

Based on the problem, the study tested the following null hypotheses:

Ho $_{1}$ : Achievement of students in physics is not significantly affected by the use of computer assisted programmed instruction

$\mathbf{H}_{\mathbf{O} 2}$ : Achievement of students in physics is not significantly affected by students' cognitive preference style.

$\mathbf{H}_{\mathbf{O} 3}$ : Achievement of the students in physics is not significantly affected by the interaction of the use of computer assisted programmed instruction and cognitive preference style.

\section{Population and Sample of the Study}

The population of the study consisted of all senior secondary two (SSII) in Abeokuta Education zone of Ogun State. SS II students were chosen because they have acquired the basis of the subject and have sufficient interest and motivation to register for physics in the senior school certificate examination. More importantly principals of secondary schools are more disposed to allow researchers to use SS II students since they were not preparing for immediate external examination.

Schools that have presented physics candidate for at least five years and have at least one physics graduate teacher were selected. The four schools were randomly assigned to two treatment conditions. One hundred and eighty six (186) students participated in the study.

\section{Instrumentation}

The study made use of the following instruments:

Physics Achievement Test (PAT).

PAT has a multiple-choice format. It has two section A and B. Section A solicited for personal information while section B has 40 items each with four options (A-D). The investigator followed the techniques of achievement test construction recommended by Okpala; Onacha and Oyedeji (1993). i.e. planning the test, item development, field testing for item analysis, selecting the final items, field testing for validity and reliability. The instrument has a $\mathrm{K}-\mathrm{R}_{20}$ reliability value of 0.83 . 


\section{Physics Cognitive Preference Inventory (PCPI)}

The PCPI was developed and used by Orji (1998) to categorise physics students into four cognitive preference areas: recall, principle, application and questioning. The PCPI, which was adopted by the researcher, comprises of two sections A and B. Section A solicited for personal information while section B has 30 items. For each item, there is an initial statement which represents some physics information. This statement is followed by four different responses (A-D) which the respondent placed in order of his/her preference by assigning 4 (most preferred) 3, 2 and 1 (least preferred). There is no right or wrong answer. The placement of the numbers 1-4, the option A-D only shows the student's preference. The pre-test of the inventory on 30 SS II physics students in Otta by the investigator showed no ambiguities in the instrument. A retest after 2 weeks produced the reliability ranging from $0.86-0.91$. the PCPI was found to be high in internal consistency reliability $\left(\mathrm{K}-\mathrm{R}_{20}=0.86\right)$

\section{Operational Guide for Conventional Method (OGCM)}

OGCM stipulates the method of teaching students in the control group. Thus the method has four main steps that are sequentially and logically dependent on each other. They are introduction, exposition, remediation and summary. Introduction involves stating the topic of the lesson, instructional objectives and linking of the new lesson with the previous one. Exposition is the step in which the teacher encourages students' active involvement in asking questions, individual and group discussion and observation. The teacher is also involved in helpful activities such as explaining prompting, thinking, discussing, clarifying concepts, asking questions and demonstrating. Remediation is the step during which the discussion and questioning are aimed at identifying students' areas of weakness for possible remedial instructions with corrective feedback. Summary is the step where the teacher provides the summary of lesson orally.

\section{Experimental and Control Group}

Students in the experimental group were exposed to computer based programmed instruction. The first week was spent on introducing the students on how to use the computer and the programme. Treatment started from the second week. The programme consisted of introduction, lesson 1, lesson 2, exit from the programme.

The students in the control group were exposed to modified lecture method of instruction initiated and executed by the teacher as stipulated in OGCM above. After treatment all the students were made to answer question in the post test.

\section{Data Analysis}

Two-way Analysis of variance (ANOVA) was used to analyse the post test since the investigator found from the pre-test scores that the schools used were equivalent and there was no significant difference in the students' achievement in the test given. Scheffe test was used as post-hoc analysis.

\section{Findings and Discussion}

\section{Hypothesis 1}

Table 1 shows analysis of variance of students' achievement score in physics by treatment and cognitive preference style. The table shows that there was a significant man effect of treatment on students' achievement in heat related concepts. $(\mathrm{F}(1,186)=28.651, \mathrm{P}<0.05)$. Thus hypothesis $\mathrm{Ho}_{1}$ was rejected. This shows that there was statistically significant effect of treatment on physics among senior secondary school students. Statistics results show that mean score of computer programmed group is 25.45 while that of control group is 21.31 . It therefore shows that students in the experimental group performed better than the conventional method group. It therefore means that the significant effect comes from computer assisted programmed instruction group.

The result supports the finding of Adesoji (1996) and Ayoola (1998) on the other hand, the result disagree with Dell (1989) and Horton et.al (1990). 


\begin{tabular}{llllll}
\hline Source of Variation & Ss & df & ms & F & sig \\
\hline Treatment & 779.738 & 1 & 779.738 & 28.651 & $0.000^{*}$ \\
Cog. Pref. Style & 1906.311 & 3 & 635.437 & 23.349 & $0.000^{*}$ \\
Treat x Cog. Pref. Style & 70.085 & 3 & 23.362 & 0.858 & 0.464 \\
Within & 8444.221 & 178 & 27.215 & & \\
Total & 106460.000 & 186 & & & \\
\hline \multicolumn{2}{c}{ *Significant at $a=0.05$} & & &
\end{tabular}

Table 1 revealed that there was a significant main effect of cognitive preference style on students achievement in physics $(\mathrm{F}(3,186)=23.349, \mathrm{P}<0.05)$. Therefore hypothesis $\mathrm{Ho}_{2}$ was rejected. This shows that there was statistically significant main effect of cognitive preference style on physics achievement of senior secondary school students in physics.

\section{Hypothesis 2}

In order to determine which of the four groups of students (Recall, Principle, Application and Questioning) achieved highest significantly, homogenous subsets test was conducted using scheffe test. Table 2 shows the group and the subsets.

Table $2 \quad$ Scheffe Test Results

\begin{tabular}{lcc}
\hline Cognitive Preference Style & \multicolumn{2}{c}{ Subset } \\
\hline & 1 & 2 \\
Recall & 19.95 & \\
Principle & 20.57 & \\
Application & & 25.21 \\
Questioning & & 28.0 \\
\hline
\end{tabular}

Table 2 shows that Questioning group achieved significantly with post-test mean score of 28.00 followed by Application group with post-test mean score of 25.21, Principle group with post-test mean score of 20.57 while the least mean score of 19.95 was associated with Recall group. The table further revealed that the achievement of students with questioning learning mode is significantly higher than the student of recall and principle respectively. The achievement of student of application learning mode is also significantly higher than those of recall and principle respectively. It therefore shows that the significant main effect comes from questioning and application. This result corroborates the findings of Tamir (1976) and Okebukola (1985). However the result contradicts the finding of Orji (1998).

The significant main effect of cognitive preference style on student achievement could be linked with the characteristics of the groups learning modes: the application group of students are learners that accept information that emphasized application in solving daily problems and the questioning group are those which critically question and analyze any information. These characteristics might have made the two groups (Application-Questioning) to achieve higher than the Recall-Principle group of students during the learning of physics concepts which is abstract and quantitative in nature (Onafowokan, 1998; Orji 1998).

\section{Hypothesis $\mathrm{Ho}_{3}$ :}

Table 1 shows that there was no significant interaction effect of treatment and cognitive preference style on student achievement in senior secondary school physics $(\mathrm{F}(3,186)=0.858, \mathrm{P}>0.05)$. Therefore, hypothesis $\mathrm{Ho}_{3}$ was accepted. This means that the impact of treatment on student achievement in physics is not sensitive to the students' cognitive preference style. This shows that the students' achievement in physics concepts as a result of exposure to treatment does not vary among students of recall, principle, application and questioning. This result when viewed against the background of the significant main effect of treatment on student achievement in physics 
concepts, tend to suggest that teachers of SS physics should used programmed instruction method in their teaching irrespective of the student cognitive preference style.

\section{Implications and Recommendations}

The implications of this study and the associated recommendations border on the following aspects of physics education - policy making; curriculum planning; in service programmes and classroom practice.

The significant effect of treatment is an indication that achievement in physics could be enhanced if practicing physics teachers adopt and imbibe computer assisted programme instruction as a physics teaching method. This could be made possible if Ministry of Education with certain policy could make computer literacy and training compulsory for sciences teachers. This will boost their chances and ability to use computer assisted programmed instruction in the teaching of physics.

It is suggested that practicing physics teachers should respect the learning mode of the students by providing extra attention to the Recall-Principle students when teaching physics concepts especially when the topic is conceptual and mathematical in nature.

The teachers of senior secondary school physics should use programmed instruction method in their teaching irrespective of the students' cognitive preference style.

\section{References}

Adesoji, F.A. (1996): The need for Computer Assisted Problem solving Instruction in Nigeria Secondary Schools. Nigerian Journal of Computer Literacy. 1.1

Ayoola, A.P. (1998): The Relative Effectiveness of Computer-Assisted and Text-Assisted Programmed Instruction on Students' Learning Outcomes in Social Studies. Unpublished Ph.D thesis, U.I.

Dell, L.M. (1989): Computer Awareness Educational level and Gender: An experimental Study with Computers and Resource Based Teaching. Unpublished Ph.D thesis. University of Pittsburg.

German, P.J. (1998): Development of the Attitude towards Science in Schools. Journal of Research in Science Teaching. 25,8.

Farayola, P.I. (2003): Effect of Computer Assisted Instruction (CAI) on Pre-NCE Students Performance in Algebraic Quadratic Equation. Journal of Science Education, 6.2

Horton, S.V; Boone, R.A. and Laitt, F.C. (1990). Teaching Social Studies to Learning Disabled High School Students. Effect of a Super Text Study Guide. British Journal of Educational Technology. 21, 2.

Heath, R.W. (1964): Curriculum, Cognitive and Educational Measurements. Educational Psychology Measurement 24.

Iroegbu, T.O. and Okpala, P.N. (1998): Problem-Based Instructional Strategy and Numerical Ability as Determinant of Senior Secondary Achievement in Physics. Studies in Curriculum 2.

Jungwirth, F. (1980): Alternative Interpretations of findings in Cognitive Preference. Research in Science Education 64. 1.

Main (2005): The Newspaper of the Physics Community Interaction. Institute of Physics March U.K.

Okebukola, P. (1998): Challenges of Science Education in the $21^{\text {st }}$ century. A keynote Address Delivered at the $2^{\text {nd }}$ National Conference of the School of Science, F.C.E. Abeokuta 23-26 June.

Okpala, P.N.; Onacha, C.O. and Oyedeji, F. (1993); Measurement and Evaluation in Education. Ibadan. Stirling-Hordan Publishers Nig. Ltd. 
Onafowokan and Okpala, P.N. (1998): Developing and Testing for Communicating Science at Junior Secondary School Level: A causal Interaction of Learner characteristics with conception of heat and temperature communicating STM. Science Teachers Association of Nigeria (STAN) proceedings.

Orji, A.B.C. (1998): Effect of Problem-Solving and Concept-Mapping, Instructional strategies on students Learning Outcomes in Physics. Unpublished Ph.D thesis U.I.

Otuka, J.O.E. (1987): Students Understanding of some concepts Physics. Journal of Science Teachers Association 25.2

Saracho,W.O. and Spodek, B. (1981): Teachers' Cognitive Style. Education Implication. The Educational Forum XLV, 2.

Tamiri, P. (1976): Relationship between Achievement in Biology and Cognitive Preference Style in High School Students. British Journal of Educational Psychology. 44.

West, S.A. (1992): Problem Based Learning: A viable Addition for Secondary School Science. School Science Review. 73. 